\title{
A Television Image System for Light Figures and Its Application to the Determination of Crystal Orientations*
}

\author{
By Jirô Watanabé**
}

\begin{abstract}
An apparatus for producing an image of light figure on a television has been designed and applied for the orientation determination of metal crystals. The apparatus consists of two main parts: one is a light-figure microscope which is provided with an optical system for producing an optical image of light figure and a goniometric mechanism for measuring the orientation angles by the light figure, and the other a television system which converts the optical image into the electrical signal and displays the light figure on the television. Full accounts are given of the construction of the apparatus and the procedure and accuracy of the orientation determination with some examples. It is shown that a clear-cut light figure can be observed on a television and the orientation work can be conducted without a dark-room. The accuracy of the determination of crystal orientations is well within $0.017 \mathrm{rad}\left(1^{\circ}\right)$.
\end{abstract}

(Received May 27, 1981)

\section{Introduction}

When a fine beam of parallel light is allowed to fall on a crystal surface etched chemically or thermally beforehand, the reflection forms on a screen a light pattern of a regular shape. This so-called light figure is produced by the reflection or scattering of light from crystallographic facets or edges of etch figures on the crystal surface. The shape of etch figures varies diversely depending upon the crystal lattice type and the etching condition. However, the arrangement of etch facets or edges in the etch figures reflects always the crystallographic symmetry of the crystal surface on which the etch figures are revealed. Consequently, the light figures show the same symmetry as that of the crystal surface concerned, and this property can be utilized for an examination of etch facets or edges developed by etching ${ }^{(1)}$ as well as for a rapid determination of crystal orientations $^{(2)}$. The present author and collaborators have so far examined the light figure phenomena with various metals, alloys, semiconductors, oxides and ionic crystals and applied them to the orientation determination.

* This paper was originally published in Japanese in J. Japan Inst. Metals, 45 (1981), 49.

** Department of Metallurgy, Mining College, Akita University, Akita 010, Japan. of single crystals and polycrystals. They have obtained some informations on the etch facets or edges ${ }^{(3)}$ and showed that the orientation determination could be conducted simply with an accuracy comparable or superior to the X-ray method ${ }^{(4)}$.

The apparatus conventionally used for the light figure observation consisted of a lamp house, a screen and a goniometer, respectively ${ }^{(5)-(9)}$. As the assembly was usually placed in a dark-room for obtaining a welldefined light figure, some inconveniences were experienced. For example, a dark-room for the exclusive use was necessary, and it must be brightly lit up at every time when the angle readings were taken on the goniometer. It is expected that such inconveniences will be overcome and moreover some advantages will be presented when we employ a television image system.

In this paper, a new design to examine the light figure on a television and its application to the orientation determination of metal crystals are presented.

\section{Apparatus}

A general view of the apparatus is shown in Photo. 1. It consists of a light-figure microscope ${ }^{(10)}$ which is fitted with a goniometer and a television image system. Figure 1 shows 


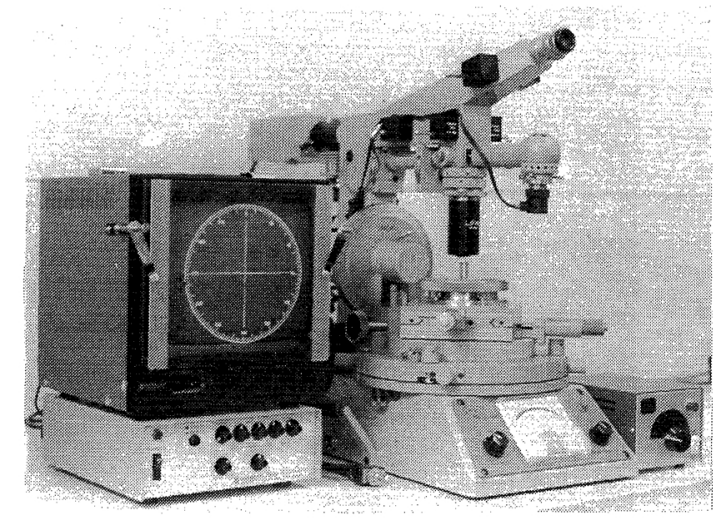

Photo. 1 Apparatus for observing light figures by means of a television image system.

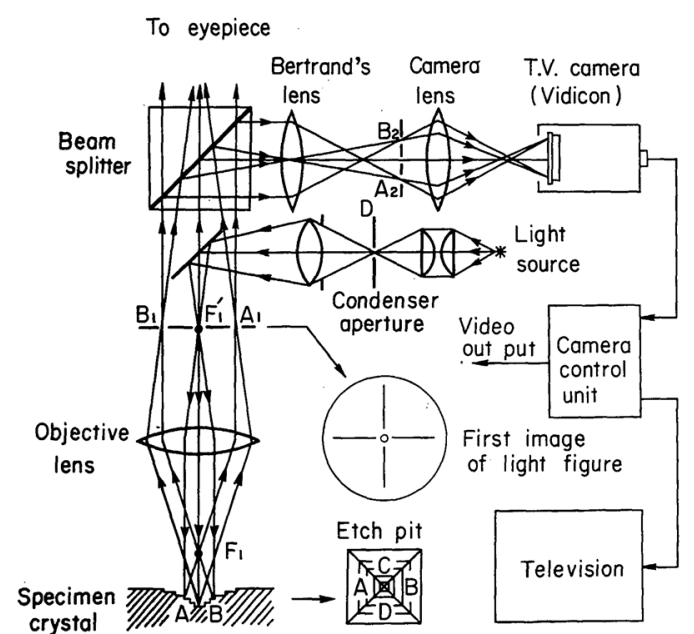

Fig. 1 Block diagram of a television image system for light figures.

in a block form a combination of the television image system with the optical system of the microscope. A light beam leaving its source (halogen lamp, 6V 20W) passes through a condenser lens, two aperture stops and an intermediate lens, and it converges at a back focus $F_{1}^{\prime}$ of an objective lens. Then, the collimated light beam falls on a limited area of an etched surface of the crystal specimen which is placed at a working distance of the objective lens. Let us suppose that the incident beam illuminates an etch pit of tetragonal pyramid shape on the (100) surface of a cubic crystal. The light beam is reflected or scattered from each terraces or edges in the etch pit, and after passed through the objective lens each components of the reflections are focussed into a cross-shaped image on the back focal plane of the objective lens. This reflectogram is the first image of the (100) light figure. The degree of collimation and the intensity of the incident light beam can be adjusted by changing a hole size of the condenser aperture stop. This size can be selected out of $6,0.4,0.2$ and $0.1 \mathrm{~mm}$ in diameter. The optical system makes a reduced image of the hole at $F_{1}^{\prime}$, so that a proper selection of the hole size can produce a highly collimated and intense light beam which results in a bright and sharp image of the light figure.

A light beam emitted from the first image of light figure is split sideways by a beam splitter and is again brought to focus into an image by the Bertrand's lens in front of a television camera. The second image thus obtained is projected through the camera lens upon a target of a television imaging tube (Vidicon) which converts the optical image into an electrical signal corresponding to the intensity of light. By means of a camera control unit, the signal input is amplified and finally the magnified optical image of the light figure can be reproduced on a television screen.

The television is of a monochromatic type (Hitachi Electronics Co., VM-90AJ) equipped with 9 inch Braun tube (screen size: $17.8 \times$ $13.4 \mathrm{~cm}$ ). A projection area of the light figure is 13 or $6 \mathrm{~cm}$ in diameter, depending upon a magnification of the camera lens. The larger size is better for a practical observation since a large light figure can be thrown on it. The dimensions of the light figure vary also with the etch pattern and the objective lens. When the etch pit comprises the etch facets sloped steeply to the original crystal plane, the light figure may become large, because components of the reflections from them converge at outer points on a back focal plane of the objective lens (see Fig. 1). However, it is to be noted that no light figure appears if the slope of etch facets is too steep to make the reflections pass through the objective lens. On the other hand, a small image may be expected with a high numerical aperture of the objective lens, because the reflections from the specified facets converge at inner points on a back focal plane of the 
lens. Moreover, the high numerical aperture may increase the image intensity owing to its wide angle convergency. The numerical apertures of objective lenses used, $\times 30$ and $\times 20$, are 0.60 and 0.40 which allow to pass the reflections from the etch facets sloped up to 0.323 and $0.201 \mathrm{rad}\left(18.5^{\circ}\right.$ and $\left.11.5^{\circ}\right)$, respectively. An example of the television images observed by use of these lenses will be given in III.

On a television screen, two straight lines, longitudinal and transverse, can be superimposed on the light figure by means of an additional device which is built in a camera control unit. For the orientation work, these lines are coordinated and taken as the reference lines which may correspond to the rotation axes of the goniometer.

It is to be noted that when the Bertrand's lens is removed out of the optical path, the surface structure of a crystal can be just in view on the television screen.

\section{Example of Television Image}

Some observations were made with $\mathrm{Cu}$ (cubic), $\mathrm{Zn}$ (hexagonal), Bi (rhombohedral) and $\beta$-Sn (tetragonal) crystals. Photograph 2 shows an etch pattern and the corresponding light figure of the (100) plane of $\mathrm{Cu}$ crystal $\dagger$. Crossshaped light figures having tiny spots at each arm tips were obtained as a result of the reflections from the terraced square pits. The patterns indicate that the appearances of light figures varied with changing hole size of condenser aperture stop and changing numerical aperture of objective lens, as expected. It is to be added that the television images of light figures are about three times as large as those obtained by the conventional apparatus ${ }^{(5)-(9)}$ and their intensity and contrast can be properly adjusted by a television control so that the observation without a dark-room can be made.

$\dagger$ An area of the crystal surface illuminated by the incident light can be changed by a selection of the hole size of a field stop. It ranges from $25 \mu \mathrm{m}$ to $1.5 \mathrm{~mm}$ in diameter with $\times 20$ objective lens and from $15 \mu \mathrm{m}$ to $0.9 \mathrm{~mm}$ in diameter with $\times 30$ objective lens, respectively. All photographs were taken from the maximum illuminating area.

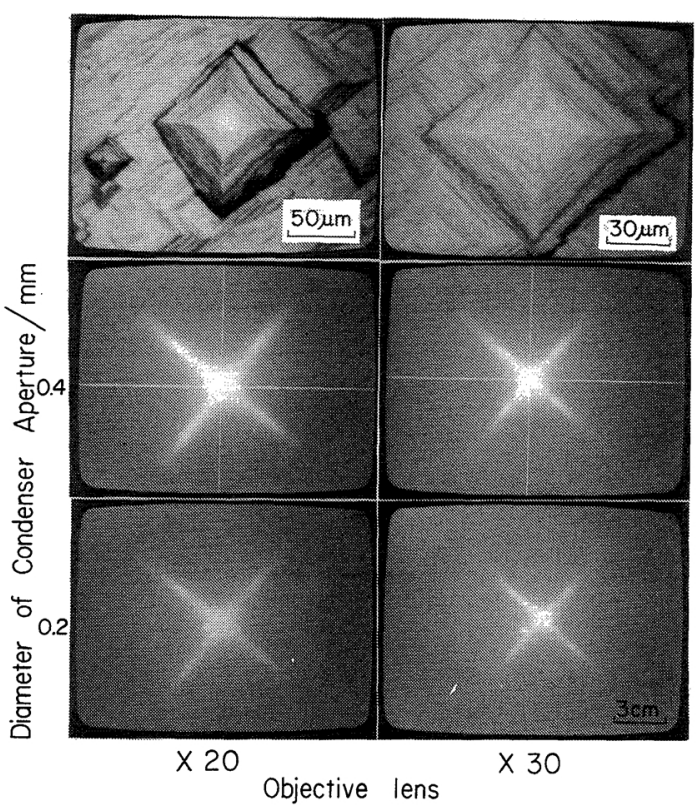

Photo. 2 Television image of etch pits and the corresponding light figures observed on the $(100)$ plane of $\mathrm{Cu}$ crystal etched with $20 \%$ aqeous solution of $\left(\mathrm{NH}_{4}\right)_{2} \mathrm{~S}_{2} \mathrm{O}_{8}$ for about $9 \times 10^{2} \mathrm{~s}(15 \mathrm{~min})$.

\section{Procedure and Accuracy of the Orientation Determination}

\section{Procedure}

When a light beam is directed perpendicularly to a low-index crystal plane, the corresponding light figure can be projected symmetrically on a television screen. For attaining such a disposition, the specimen crystal and/or the incident light beam are properly rotated by the goniometer. Figure 2 illustrates a geometrical arrangement of the rotation axes of the goniometer, the incident light beam and the specimen crystal. We take a rectangular coordinate system, XYZ, of which the $\mathrm{X}$ axis coincides with the rotation axis of the vertical circle and the $\mathrm{Z}$ axis coincides with that of the horizontal circle of the goniometer. For a practical convenience, let us suppose that a crystal plate is set in such a position that its long axis $\overrightarrow{\mathrm{OP}}$ may coincide with the $Y$ axis and its flat surface may lie parallel to the $X Y$ plane (the surface normal $\overrightarrow{\mathrm{OZ}}$ may inevitably coincide with the $\mathrm{Z}$ axis). Then, the beam direction can be 


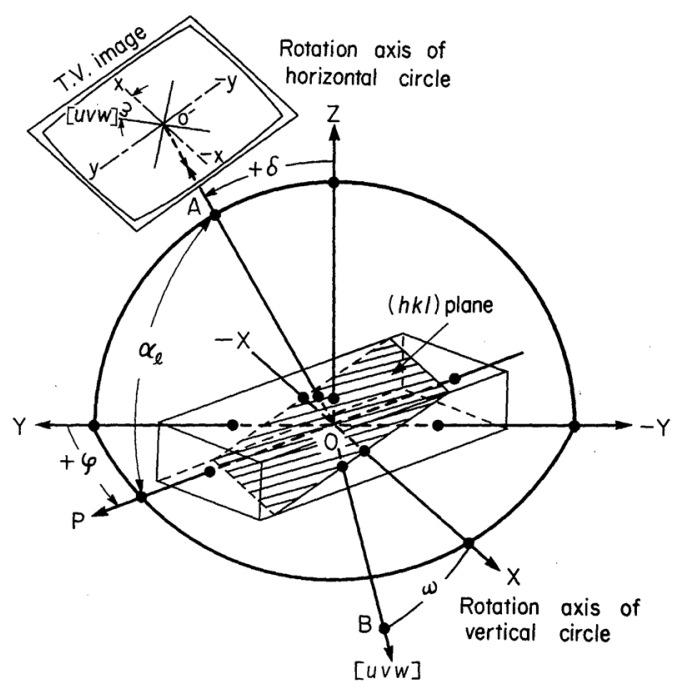

Fig. 2 Illustration for a geometrical arrangement of the rotation axes of goniometer, the incident light beam and the specimen crystal.

brought in alignment with a normal $\overrightarrow{\mathrm{OA}}$ of the low-index $(h k l)$ plane by rotating the horizontal circle by an angle $\varphi$ and then the vertical circle by an angle $\delta$, respectively, and the $(h k l)$ light figure is thrown symmetrically around a point $\mathbf{o}^{\prime}$ on a television screen which may correspond to an intersection of the light beam direction with the screen. The point $o^{\prime}$ is preliminarily displayed in its position in the following way. An optically flat glass is mounted on the XY plane (specimen stage) and the incident light beam is allowed to fall vertically on it by setting the vertical circle at zero point. This makes a tiny light spot on the screen which corresponds to $o^{\prime}$. Then, two lines, longitudinal and transverse, are displayed on the screen and adjusted so as to cross at $o^{\prime}$ in a situation that a trace of the light spot when the vertical circle is rotated is followed up on the transverse line. Two lines thus coordinated, $x$ and $y$, are the reference lines which may correspond to the $-\mathrm{X}$ and $\mathrm{Y}$ axes, respectively. The upside-down projection of the $x$ line against the $X$ axis may be due to an imaging system used.

A procedure to be taken for the orientation determination is as follows. The crystal plate is first mounted horizontally on the specimen stage (the XY plane in Fig. 2), and its side edge parallel to the long axis $\overrightarrow{\mathrm{OP}}$ is brought in aljgnment with a scribed line on it (the $\mathrm{Y}$ axis in Fig. 2). Then, the goniometer is so adjusted that a symmetric center of the $(h k l)$ light figure may coincide with the center $o^{\prime}$ of reference lines $\mathrm{x}$ and $\mathrm{y}$ on the television screen as shown in Photo. 2, and the angle readings of the goniometer, $\delta$ and $\varphi$, are recorded. Then, the angles $\alpha_{l}$ and $\alpha_{n}$ which the long axis $\overrightarrow{\mathrm{OP}}$ and the surface normal $\overrightarrow{\mathrm{OZ}}$ make with the normal of $(h k l)$ plane are given from Fig. 2 by the following expressions, respectively:

$$
\left.\begin{array}{c}
\cos \alpha_{l}=\sin \delta \cos \varphi, \\
\alpha_{n}=\delta .
\end{array}\right\}
$$

For a cylindrical rod crystal, the specimen crystal is held horizontally in a V type groove of the specimen stage ${ }^{(10)}$, and the angle $\alpha_{l}$ is referred to the cylindrical axis. Moreover, the ( $h \mathrm{kl}$ ) light figure can be brought into the required position by rotating the specimen crystal about its cylindrical axis and by rotating the vertical circle by an angle $\delta$ without rotating the horizontal circle from the zero point. Then, the angle $\alpha_{l}$ is obtained from

$$
\alpha_{l}=\pi / 2-\delta
$$

To determine the orientation of the specimen axis with respect to the principal crystallographic axes, at least two crystallographic measurements are necessary for the two degrees of freedom. This must be satisfied by repeating the above procedure with one more light figure. However, it must be mentioned that if the crystal plane inclines steeply to the crystal surface, the corresponding light figure becomes asymmetric so that the accurate measurement is impossible. Usually, two favourable light figures can be obtained for most orientations of a high symmetry crystal ${ }^{(11)(12)}$ and a few special orientations of a low symmetry crystal, but not for other many crystals.

To determine the crystal orientation by use of only one light figure, the following procedure can be successfully applied. We assume, in Fig. 2, that a cross-shaped light figure which corresponds to the (100) plane of a cubic crystal is projected symmetrically on a television screen. Then, each arm radiating from its 
center may correspond to the zone axes $\langle u v w\rangle$ which lie on the (100) plane. For example, the four arms of the $\mathrm{Cu}(100)$ light figure shown in Photo. 2 are indexed as [010], [001], [010] and [001] axes, respectively. If a $[u v w]$ arm makes an angle $\omega$ with the reference line $x$, we can take the $[u v w]$ axis as $\overrightarrow{\mathrm{OB}}$ on the (100) plane which makes the same angle with the $X$ axis (see Fig. 2). From the geometrical relationships, we obtain

$$
\left.\begin{array}{l}
\cos \beta_{l}=\sin \varphi \cos \omega+\cos \varphi \sin \omega \cos \delta, \\
\cos \beta_{n}=-\sin \omega \sin \delta .
\end{array}\right\}
$$

From these the angles $\beta_{l}$ and $\beta_{n}$ which the $[u v w]$ axis makes with the long axis $\overrightarrow{\mathrm{OP}}$ and the surface normal $\overrightarrow{\mathrm{OZ}}$ of a crystal plate can be calculated, respectively. For a cylindrical crystal, the angle $\beta_{l}$ is referred to the cylindrical axis, and when the measurements are conducted without rotating the horizontal circle as stated before, the angle $\beta_{l}$ is given by

$$
\cos \beta_{l}=\sin \omega \cos \delta \text {. }
$$

Photograph 3 shows a protractor for the measurement of the angle $\omega$. A graduation $2 \pi\left(360^{\circ}\right)$ divided into $\pi / 90\left(2^{\circ}\right)$ is engraved on a transparent plate of a plastic material. The engraved circle is $13 \mathrm{~cm}$ in diameter equal to that of a projecting area of light figure on a television. This protractor is fixed concentrically onto the television frame in such a way that 0-180 and 90-270 lines may coincide with the

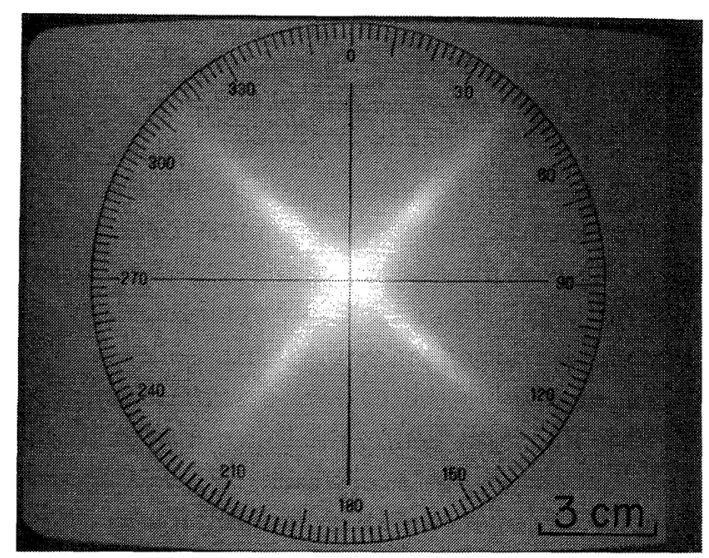

Photo. 3 Protractor used for measuring an azimuthal angle $\omega$ of the $[u v w]$ arm of light figure on a television screen. reference lines $x$ and $y$ on the screen, respectively, and the angle reading is taken by an indication of the $[u v w]$ arm.

It is to be noticed that a stereographic projection is used to facilitate handling of the data, as will be illustrated in the next section.

\section{Example and accuracy}

Table 1 gives a result of measurements of angles $\delta, \varphi$ and $\omega$ when used $\mathrm{Cu}(100)$ light figure and its [001] arm as revealed by etching with $20 \%$ aqueous solution of ammoniumpersulphate for about $9 \times 10^{2} \mathrm{~s}(15 \mathrm{~min})$. It can be seen that the angles $\delta$ and $\varphi$ can be measured with an accuracy well within 0.0087 $\operatorname{rad}\left(0.5^{\circ}\right)$ and the angle $\omega$ within $0.017 \mathrm{rad}$ $\left(1^{\circ}\right)$, respectively. Some examples of orientations of single crystal rods of $\mathrm{Cu}$ and $\mathrm{Bi}$ as calculated from the measured data are given in Table 2 , in which $\alpha, \beta$ and $\gamma$ for $\mathrm{Cu}$ crystal are angles between the rod axis and the [100], [010] and [001] axes, and $\theta, \alpha, \beta$ and $\gamma$ for $\mathrm{Bi}$ crystal are those with [111], [101]], [01̄] and [110] axes, respectively. The orientations as determined by the fundamental procedure using two light figures ${ }^{(5)}$ and by the backreflection Laue method ${ }^{(13)}$ are also given for comparison in the same table, from which it can be found that all the data agree well with each other.

Figure 3 illustrates the method of plotting the goniometric data on a stereographic projection. The data given in Table 1 is plotted. The projection on the (100) plane can be conveniently used, as can be visualized in comparison with Fig. 2. On a circumference of the basic circle, a point $X$ is plotted apart by an angle $\omega=0.826 \mathrm{rad}\left(47.3^{\circ}\right)$ from the 001 pole and a point $\mathrm{Y}^{\prime}$ is plotted $\pi / 4 \mathrm{rad}\left(90^{\circ}\right)$ apart from $X$. Then a diameter passing through $\mathrm{Y}^{\prime}$

Table 1 An example of the measurement of angles $\delta, \varphi$ and $\omega$ by use of the (100) light figure and its [001] arm of $\mathrm{Cu}$ crystal.

\begin{tabular}{cccc}
\hline \hline & $\delta \operatorname{rad}\left({ }^{\circ}\right)$ & $\varphi \operatorname{rad}\left({ }^{\circ}\right)$ & $\omega \operatorname{rad}\left({ }^{\circ}\right)$ \\
\hline 1 & $+0.087(5.0)$ & $+0.370(21.2)$ & $0.820(47)$ \\
2 & $+0.084(4.8)$ & $+0.379(21.7)$ & $0.820(47)$ \\
3 & $+0.082(4.7)$ & $+0.382(21.9)$ & $0.838(48)$ \\
\hline Mean & $+0.084(4.8)$ & $+0.377(21.6)$ & $0.826(47.3)$ \\
\hline \hline
\end{tabular}


Table 2 Orientations of single crystal rods of $\mathrm{Cu}$ and $\mathrm{Bi}$ as determined by the present method.

\begin{tabular}{|c|c|c|c|c|c|c|c|c|c|}
\hline Crystal & $\begin{array}{l}\text { Light } \\
\text { figure }\end{array}$ & $\begin{array}{c}\text { Zone } \\
\text { axis }\end{array}$ & $\underset{\left({ }^{\circ}\right)}{\delta \mathrm{rad}}$ & $\varphi \underset{\left({ }^{\circ}\right)}{\mathrm{rad}}$ & $\underset{\left({ }^{\circ}\right)}{\omega \mathrm{rad}}$ & $\underset{\left({ }^{\circ}\right)}{\theta \mathrm{rad}}$ & $\underset{\left({ }^{\circ}\right)}{\alpha \mathrm{rad}}$ & $\underset{\left({ }^{\circ}\right)}{\beta \mathrm{rad}}$ & $\underset{\left({ }^{\circ}\right)}{\gamma \operatorname{rad}}$ \\
\hline \multirow{6}{*}{$\mathrm{Cu}$} & (100) & [001] & $\begin{array}{l}+0.084 \\
(+4.8)\end{array}$ & $\begin{array}{l}+0.377 \\
(+21.6)\end{array}$ & $\begin{array}{l}0.826 \\
(47.3)\end{array}$ & - & $\begin{array}{l}1.492 \\
(85.5)\end{array}$ & $\begin{array}{l}1.204 \\
(69.0)\end{array}$ & $\begin{array}{l}0.375 \\
(21.5)\end{array}$ \\
\hline & (100) & [001] & $\begin{array}{l}+0.077 \\
(+4.4)\end{array}$ & $\begin{array}{c}0 \\
(0)\end{array}$ & $\begin{array}{l}1.248 \\
(71.5)\end{array}$ & - & $\begin{array}{l}1.494 \\
(85.6)\end{array}$ & $\begin{array}{l}1.250 \\
(71.6)\end{array}$ & $\begin{array}{l}0.332 \\
(19.0)\end{array}$ \\
\hline & (100) & [001] & $\begin{array}{l}-0.070 \\
(-4.0)\end{array}$ & $\begin{array}{c}0 \\
(0)\end{array}$ & $\begin{array}{l}1.890 \\
(108.3)\end{array}$ & - & $\begin{array}{l}1.501 \\
(86.0)\end{array}$ & $\begin{array}{l}1.251 \\
(71.7)\end{array}$ & $\begin{array}{l}0.326 \\
(18.7)\end{array}$ \\
\hline & $(0 \overline{1} 0)$ & [100] & $\begin{array}{l}-0.323 \\
(-18.5)\end{array}$ & $\begin{array}{l}-0.103 \\
(-5.9)\end{array}$ & $\begin{array}{c}0 \\
(0)\end{array}$ & - & $\begin{array}{l}1.468 \\
(84.1)\end{array}$ & $\begin{array}{l}1.250 \\
(71.6)\end{array}$ & $\begin{array}{l}0.339 \\
(19.4)\end{array}$ \\
\hline & \multicolumn{5}{|c|}{ Mean value } & - & $\begin{array}{l}1.489 \\
(85.3)\end{array}$ & $\begin{array}{l}1.238 \\
(71.0)\end{array}$ & $\begin{array}{l}0.347 \\
(19.6)\end{array}$ \\
\hline & $\begin{array}{l}(100) \\
(010)\end{array}$ & \multicolumn{4}{|c|}{ By two light figures ${ }^{(5)}$} & - & $\begin{array}{l}1.485 \\
(85.1)\end{array}$ & $\begin{array}{l}1.236 \\
(70.8)\end{array}$ & $\begin{array}{l}0.347 \\
(19.9)\end{array}$ \\
\hline \multirow[t]{2}{*}{$\mathrm{Bi}$} & $(\overline{111})$ & {$[10 \overline{1}]$} & $\frac{-0.021}{(-1.2)}$ & $\begin{array}{c}0 \\
(0)\end{array}$ & $\begin{array}{l}2.900 \\
(166)\end{array}$ & $\begin{array}{l}1.550 \\
(88.8)\end{array}$ & $\begin{array}{l}0.279 \\
(14.0)\end{array}$ & $\begin{array}{l}1.850 \\
(106.0)\end{array}$ & $\begin{array}{l}2.337 \\
(133.9)\end{array}$ \\
\hline & \multicolumn{5}{|c|}{ Back-reflection Laue method ${ }^{(13)}$} & $\begin{array}{l}1.534 \\
(87.9)\end{array}$ & $\begin{array}{l}0.220 \\
(12.6)\end{array}$ & $\begin{array}{l}1.878 \\
(107.6)\end{array}$ & $\begin{array}{l}2.311 \\
(132.4)\end{array}$ \\
\hline
\end{tabular}

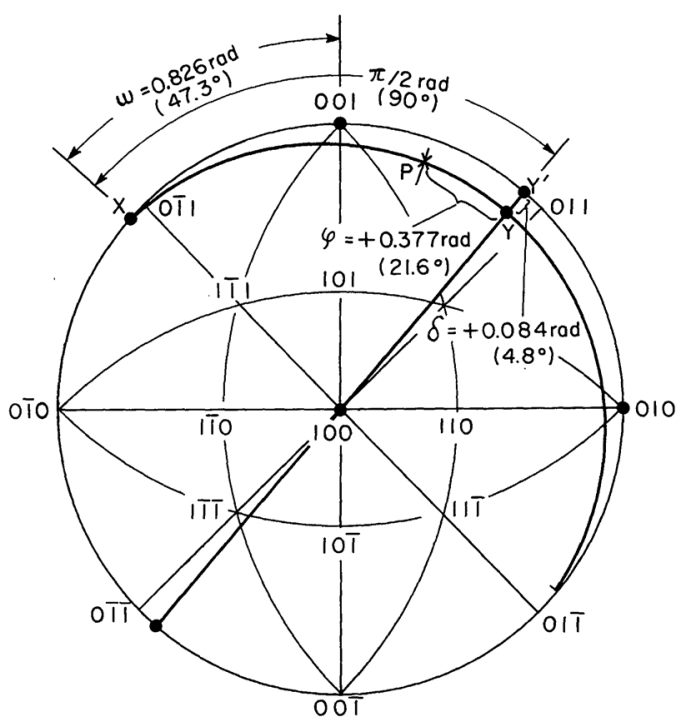

Fig. 3 Stereographic plot of an orientation of $\mathrm{Cu}$ crystal from the measured value of angles $\delta, \varphi$ and $\omega$ given in Table 1.

is drawn and a point $\mathrm{Y}$ is taken on it at an angular distance $\delta=+0.084 \mathrm{rad}\left(4.8^{\circ}\right)$ from $\mathrm{Y}^{\prime}$. It is seen that the poles $\mathrm{X}$ and $\mathrm{Y}$ thus obtained correspond to the $X$ and $Y$ axes of the $X Y Z$ coordinate system in Fig. 2. Then, the meridian $\overparen{X Y}$ is drawn and the rod axis is taken on it as a point $\mathrm{P}$ distant by an angle $\varphi=+0.377 \mathrm{rad}\left(21.6^{\circ}\right)$ from Y. Readings of the angles $\alpha, \beta$ and $\gamma$ obtained from the above projection are $1.94 \mathrm{rad}\left(85^{\circ}\right), 1.26 \mathrm{rad}\left(72^{\circ}\right)$ and $0.35 \mathrm{rad}\left(20^{\circ}\right)$ which are in good agreement with those given in Table 2.

\section{Conclusion}

A television image system for light figures was tested and applied to the orientation determination of metal crystals. With the new design, a bright and sharp light figure could be projected on an area as large as $13 \mathrm{~cm}$ in diameter and the orientation determination could be conducted without a dark-room. The procedure and accuracy of the orientation determination were illustrated with reference to some examples, and it was shown that the crystal orientation could be simply determined with an accuracy well within $0.017 \mathrm{rad}\left(1^{\circ}\right)$.

\section{Acknowledgements}

The television image system was designed in cooperation with Messrs. T. Terao and $\mathrm{K}$. Kato of Union Optical Co. Ltd. The author sincerely appreciates their efforts. $\mathrm{He}$ is also grateful to the late Emeritus Professor M. Yamamoto of Tohoku University for the continuing encouragement. This work was partially supported by a Grant-in-Aid for Developmental Research from the Ministry of Education. 


\section{REFERENCE}

(1) B. D. Cuming and A. J. W. Moore: J. Australian Inst. Metals, 3 (1958), 124.

(2) B. Chalmers: Proc. Roy. Soc. (London), 47 (1935), 733.

(3) For example, M. Yamamoto and J. Watanabé: Kesshô Kôgaku Handbook, Kyôritu Pub. Co., Tokyo, (1971), 283.

(4) M. Yamamoto and J. Watanabé: Sci. Rep. Res. Inst. Tohoku Univ., A9 (1957), 24.

(5) M. Yamamoto: Sci. Rep. Tohoku Univ., 31 (1943), 121.

(6) A. J. Goss: British J. Sci. Instr., 30 (1953), 283.
(7) F. Haessner, W. in der Schmitten: Z. Metallk. 49 (1958), 507.

(8) M. Yamamoto and J. Watanabé: Sci. Rep. Res. Inst. Tohoku Univ., A17 (1965), 243.

(9) H. Gengnal and W. Schwab: Z. Metallk. 37 (1966), 281.

(10) J. Watanabé, M. Yamamoto, T. Tameto and K. Kato: Trans. JIM, 13 (1972), 50.

(11) M. Yamamoto and J. Watanabé: Sci. Rep. Res. Inst. Tohoku Univ., A7 (1955), 173.

(12) M.Yamamoto and J. Watanabé: ibid., A9 (1957), 395.

(13) J. Watanabé: Sci. Rep. Res. Inst. Tohoku Univ., A8 (1956), 385. 